\title{
Influences of Packaging and Labeling Aspects on Consumer Preferences for Personal Care Products: An Empirical Study on the Rural Consumers of Chittagong Division, Bangladesh
}

\author{
Stanley Sumon Rodrick ${ }^{1}$, Hamidul Islam², Ahmed Ishtiaq Zadid ${ }^{3}$ \\ ${ }^{1}$ Assistant Professor, American International University-Bangladesh (AIUB) \\ ${ }^{2}$ Assistant Professor, American International University-Bangladesh (AIUB) \\ ${ }^{3}$ BBA Student, American International University-Bangladesh (AIUB)
}

\begin{abstract}
The rural markets are contributing around 65 percent of the total consumption in Bangladesh. Due to the socioeconomic conditions and infrastructural facilities, rural markets are diverse from the urban settings. This study emphasizes on the influences of packaging and labeling aspects in the definitive decision making of the rural consumers in Bangladesh. The research represents the issue covering the consumers' behavioral pattern in the selected areas of the Chittagong Division in Bangladesh. The research exploration comprises of four aspects, i.e. views about packaging, comprehension of the illustrated communications, capability in identifying and response towards the copy products and expectations for further improvements in packaging and labeling of the personal care products. The researcher(s) emphasized to figure out the above-mentioned facts by portraying the behavior of respondents by a three-month long study from three remote villages conveniently chosen. A total of 200 respondents were interviewed from the selected areas on the mentioned statement. The collected responses were analyzed statistically. For understanding the influence of rural respondents' level of age, education, and income variables on their consumption behavior, hypotheses were tested by applying the "Z-test technique". It has been found that packaging of a product influences the rural consumers' buying behavior; the shape is the most aesthetical feature which attracts the consumers, retailer's role in facilitating the consumers in distinguishing actual versus copy products and positive responsiveness on the illustrated information about the original product. It further concluded that improvements in packaging and labeling elements can better reinforce consumers' acceptance towards products.
\end{abstract}

KeyWords: Rural Marketing, Personal Care Products' Packaging, Labeling, Copy Products, Communications

\section{Introduction}

At least 40 percent of the world's total markets constitute the rural markets. It represents more than three billion people whose current consumption is estimated to be at least Four Trillion US Dollar per year [1]. The rural areas of Bangladesh comprises around 65 percent of sale generations, making it one of the bigger consumer markets in the country. Rural markets are diverse than the urban markets in terms of the environment, educational attainment, income levels, occupational structures, socio-cultural factors, psychology, consumption pattern and so on. Therefore, different initiatives and strategies are required for penetrating the rural markets. In recent times, it has been observed that many Fast Moving Consumer Goods (FMCG) companies in Bangladesh are giving substantial endeavors in the rural markets for making their products acceptable and eventually leveraging their profitability margin. Previous researches have shown that there is no agreement on overall classification of packaging materials and package elements. There are also disagreements regarding the methods 
of packaging impact on consumer's purchase decision. Some researchers have explored the impact of packaging and its features on consumer's overall purchase decision [2]. Packaging is an important aspect of the branding process, as it plays a vital role in communicating the image and identity of a company. The packaging design is chosen as the various elements and blended into a holistic design to achieve a particular sensory effect [3]. Nowadays, the packaging is considered as an essential element in terms promoting a product. Durable packaging and stimulating aesthetics can seek the attention of the potential customers, especially in the rural areas. Packaging appeals on consumer's responsiveness towards a certain brand, this increases its brand image, and stimulates consumer's perceptions about a product [4]. A consumer brand experience impacts on customer satisfaction and brand loyalty [5]. Manufacturers must understand responses of consumer packages of a company [6]. The company should design the packaging that covers specific elements, such as size, shape, materials, color, pattern, text and the brand mark [7]. Personal care products are the products are which used in personal hygiene and for beautification [8]. For this research purpose, the researchers have taken six different types of personal care products such as soap, shampoo, hair oil, talcum powder, body lotion and face-cream due to the regular use of these products in the rural areas.

\subsection{Objectives of the Study}

$>$ To explore how packaging and labeling aspects can influence rural consumers to purchase their desired personal care products.

$>$ To measure the relative impact of packaging based on the age, education and income level.

$>$ To determine how they perceive the instructions written on the package label.

$>$ To investigate their aptitude in identifying the genuine products versus counterfeit fake products.

\section{Review of Related Literature}

Packaging plays a vital role in the promotion of any good. Packaging design variables mainly constituted the following components: color, typography, pictures, shape, size, and materials [9]. Shape plays a crucial role in developing an image in the consumers' mindset and facilitates the offerings into a renowned identity. Besides materials used in packaging, it also affects the consumers' mindset and assures the acceptability of the product [10]. Appropriate and vivid picture or packaging color, delivers the users a happy feeling, at the same time an easy to handle packages, packaging shapes contribute in raising consumers' attention and interest [11]. Underwood (2001) noted that pictures on packages increased learning and were considered more vibrant stimuli than verbal explanations. Color, picture, graphical illustration uphold a greater interest in the younger ones prior to the older family members, at the same time it attracts those who cannot read the information portrayed. Packaging pictures increase shoppers' attention to the brand [12]. The result showed that packaging pictures were used for private label brands and /or less tire national brands whose strategic objectives were to improve consumers' perceptions of the brand. In another study conducted by Underwood (2003), proposed that consumers linked meanings to the package colors in three different groups namely 'the physiological', 'the cultural', and 'the associational'. He has also discussed the significance of pack size in the visibility of packaging and information display [13]. The graphical component of the package influenced consumer beliefs even when the verbal component of the package provided accurate product attribute information [14]. The results showed that the graphical component of the label could significantly influence the attribute beliefs and purchase intentions even when the verbal component of the package was held constant and provided accurate product attribute information. Underwood (2003) pointed out that, unlike the transmission of positioning through advertising, packaging allows positioning to be transferred live [15]. Packaging refers to all those activities related to designing, evaluating and producing the container for a product. At the same time "Labeling" refers to the display of information about a product on its container, wrapper, or the product itself. For several types of consumer and industrial products, the type and extent of information that must be imparted by a label are governed by the relevant safety and shipping laws [16]. The impact of packaging and its elements can impact on 
the consumer's purchase decision. According to the findings of Bassin (1988), five key areas in packaging which provides value addition to consumers are brand identification; advertisement at the point-of-sale; facilitates consumers' in handling the product; improving home storage facility and adding value by providing task assistance [17]. Another study proposed a normative framework to direct the design of effective communication in product packaging. The authors suggested that a set of norms (truthfulness, sincerity, comprehensibility, legitimacy) could direct the complex task of designing good product packaging [18]. The fake market is one of the biggest threats in the rural markets. Major brands and products are facing huge problems with the counterfeit products. Rural markets suffer from problems of low penetration and poor availability of branded products and this facilitates the local companies to use the name of branded products and release the counterfeit products in the local market. Thus, the parent company is detached from making the profits where these local companies generate greater revenue through such sales in the respective markets to falsify, deceive, or defraud the customers. A copy or imitation of something that is intended to be taken as authentic and genuine to deceive another is known as the counterfeit product. [19]. The counterfeit or fake products can be divided into three distinct categories: look-alikes; spell-alike and duplicates [20]. Manjunatha (2004) put forth that the consumption pattern of rural people has increased in recent years. The rural consumer wants to acquire the urban lifestyle in their buying behavior and it is reflected in their buying decisions [21].

\section{Methodology}

Structured questionnaires were developed with determinant multiple choices phrasing to collect the data from the rural consumers and retailers. The rural residents were interviewed by one to one home visits and focus group discussions. The study was conducted in three different rural locations of the Chittagong division of Bangladesh, which were Jongolbari, Banshkhali, and Char Jangalia villages from Comilla, Chittagong, and Lakshmipur Districts respectively. Rural males and females from the age range between 18-59 years were selected as the target population for the study. A total of 200 respondents were interviewed (117 males and 77 females) and they were selected based on non-probability sampling frame by the researchers. The questionnaire was the combination of close ended questions along with simple dichotomies. To interpret the study, "Z-test Technique" has been applied for analyzing the outcomes of the study.

\section{Analysis \& Interpretation}

To study the impact of packaging \& labeling aspects of personal care products in the rural consumer's behavior, the consumer base was divided into three broad groups which were based on their socioeconomic characteristics, such as the level of education, age, and monthly income. All the components are divided into two groups. First of all, for the age factor, it was divided into 18 to 45 years as one group and from 46 to 59 years into another group. For demystifying the educational dimension, one group has been developed as No educational attainment to primary school level (up to the $5^{\text {th }}$ standard), one group from high school level [ $6^{\text {th }}$ standard to Masters Level along with the vocational education category (if any)]. Finally, for figuring out the significance of the income level, the researchers have divided the group into two sets. One group is for the income earners between 0- 20,000 BDT (Bangladeshi Taka), another group from 20,001- 40,000 BDT. Three different hypotheses were tested by using "Z-test" table in order to get the respective results and to show how much these indicators influence rural consumers in their buying behavior of personal care products. Again, as the questionnaire contains both qualitative and quantitative nature and to simplify those, it had been divided into positive or negative responses. The responses which support the statement counted as positive responses and which opposes the statement is counted as the negative responses. It is to be noted that the option "Sometimes" is also counted as a positive response. On the other hand, from the questionnaire, the questions which were in simple dichotomies contain valuable insights of the respondents, so all the responses have been counted as positive responses. 
Hypothesis: 1 - Rural Consumers age does not influence on purchasing behavior by the packaging of the personal care products.

TABLE I: Distribution of the respondents' response based on the Age

\begin{tabular}{|c|c|c|c|c|}
\hline Group & Age & Number of Responses & Positive Responses & Negative Responses \\
\hline \multirow{4}{*}{ Group-1 } & $18-24$ & 38 & 32 & 6 \\
\cline { 2 - 5 } & $25-31$ & 57 & 51 & 6 \\
\cline { 2 - 5 } & $32-38$ & 43 & 40 & 3 \\
\cline { 2 - 5 } & $39-45$ & 28 & 26 & 2 \\
\hline \multirow{2}{*}{ Group- 2 } & $46-52$ & 19 & 4 & 15 \\
\cline { 2 - 5 } & $53-59$ & 15 & 5 & 10 \\
\hline
\end{tabular}

Hypothesis: 2 - Level of education of the rural consumers have no influence over the packaging and the labeling aspects of the personal care products.

TABLE II: Distribution of the respondents' response based on the Education

\begin{tabular}{|c|c|c|c|}
\hline Education Level & Number of Responses & Positive Responses & Negative Responses \\
\hline No Educational Attainment-Primary & 90 & 25 & 65 \\
\hline High School-Masters/Vocational & 110 & 98 & 12 \\
\hline
\end{tabular}

Hypothesis: 3 - Level of income of the rural consumers does not influence their preferences on the packaging of the personal care products.

TABLE III: Distribution of the respondents' response based on the Monthly income

\begin{tabular}{|c|c|c|c|}
\hline Monthly Income & Number of Responses & Positive Response & Negative Responses \\
\hline Below BDT 10,000 - BDT 20,000 & 58 & 20 & 38 \\
\hline BDT 20,001 - Above BDT 40,000 & 142 & 120 & 22 \\
\hline
\end{tabular}

For all three hypotheses, the null hypothesis is,

$\mathbf{H}_{\mathbf{0}}: \prod_{1}=\prod_{2}$

If not true, alternative hypothesis is,

$\mathbf{H}_{\mathbf{0}}: \prod_{1} \neq \prod_{2}$ or $\prod_{1}>\prod_{2}$

Again,

$\mathrm{N}_{1}=$ Population Group-1 $\quad \mathrm{X}_{1}=$ Positive Responses- $1 \quad \mathrm{~N}_{2}=$ Population Group $-2 \quad \mathrm{X}_{2}=$ Positive Responses -2

$\therefore \mathrm{P}_{1}=\mathrm{X} 1 / \mathrm{N} 1$

Hence,

$\mathrm{P}={ }^{\mathrm{N} 1 \mathrm{P} 1+\mathrm{N} 2 \mathrm{P} 2 / \mathrm{N} 1+\mathrm{N} 2}$

$={ }^{\mathrm{X} 1+\mathrm{X} 2} / \mathrm{N} 1+\mathrm{N} 2$

At $5 \%$ level of significance, the critical value of $\mathrm{Z}$ is $=0.005=1.96$. If calculated value of $\mathrm{Z}$ appears greater than 1.96 than the null hypothesis is rejected and the alternative hypothesis is accepted.

Based on the $\mathrm{Z}$ test Technique the result for the hypothesis(s) stands as-

\begin{tabular}{|c|c|c|}
\hline Hypothesis-1 & Hypothesis-2 & Hypothesis-3 \\
\hline 8.42 & 9.10 & 11.50 \\
\hline
\end{tabular}

As the result of the entire Hypothesis is more than 1.96. So, the alternative hypothesis is accepted which is $\mathbf{H}_{\mathbf{0}}: \prod_{1} \neq \prod_{2}$ or $\prod_{1}>\prod_{2}$

Therefore, all the three indicators such as age, education and income of rural consumers show a strong and positive influence on their buying behavior regarding the use of personal care products.

Mostly the millennial's (generation cohort born roughly between 1980-2000); the age bases from 18-31 years are attracted by the packaging of a product, on the other hand, respondents aged between 32-59 
considers that packaging as a tool of product's protection and an appealing factor for the promotion, but sometimes an innovative and attractive packaging can also influence their buying behavior.

A majority of rural consumers prefer packaging which assures the protection of the final purchase of their desired product/s. This identified factor is followed by the 'attractiveness' of the packaging. They do so mostly by considering the preference of the younger members of the family. Through indetailed discussions, it was also obvious that the rural consumers do not possess a sound knowledge regarding eco-friendly packaging.

$>$ Based on the responses, the top preference of rural consumers is that the 'shape' of packaging. The second preference is regarding the 'color' content. Mostly rural women and young adults prefer such features. From the in-depth discussions, it was found that they prefer transparent packages as it can assist them to look into the product and verify the quantity provided in the packaged product.

$>$ From the study, it is evident that a significant proportion of the respondents are less aware of the instructions mentioned in the labeling of the product. Some of the identified reasons for not following the instructions properly are; as they are well equipped with the usage of the products on their regular basis they are less interested to follow the usage instructions; if they are unable to understand any mentioned instruction provided on the label, they seek the assistance of their family members to comprehend the given information; and lastly if the instructions are not actually understandable either by themselves or their family members, then they seek the assistance of the rural retailers.

$>$ A majority of the respondents have mentioned that they do not always read the dates stated in the packages such as the manufacturing date, expiry date, or sometimes the best before date of the product. A significant proportion of the female consumers' segment is not totally concerned about the mentioned issue. It is also identified through discussions that, certain groups of consumers who are aware of the mentioned instructions sometimes face difficulty in terms of reading the proper instructions due to faded ink or the smaller font sizes printed on the product's label.

$>$ Some of the respondents mentioned that they are aware that the stated Maximum Retail Price (MRP) of the product is printed, but they do not always observe or cross-check the price at the time of purchase. In such situation, they totally rely on the retailer's transaction approach, instead of verifying the actual paid amount with the mentioned MRP.

$>$ One of the key objectives of this study is to determine whether the rural consumers are able to differentiate actual products versus copy products. From the responses, it has been found that 58 percent of the rural consumers can identify the actual versus fake products. A significant portion still remains in the darkness as they are unable to figure out the authenticity of a product by themselves.

$>$ From the respondents, it has been identified that the rural retailers play a vital role in assisting the consumers to identify the actual products. Secondly, comparing the price with the actual products rural consumers figure out that the product is genuine or not. Due to various reasons, rural consumers visit the nearby towns on a regular basis. By doing so, they are exposed to different brands of personal care products. By the discussion with the respondents, it can be identified that male customers are having such opportunity to differentiate the brands with the price offered and eventually they can figure out the authenticity of the products by comparing the price. Whereas, the female customers do not always have such kind of opportunity to verify the price in terms of identifying actual versus copy products. Around 8 percent of the respondents, mentioned that by physically using the product, then only they can identify the authenticity of the products. A significant portion identifies the difference by reading the manufacturer's name, logo, package design, shape and other variables.

$>$ It is also identified that around 32 percent of the respondents would continue to use the copy products as part of their regular usage. One of the possible reasons for these consumers to use the copy products is the unavailability of the original branded products. Many of the renowned branded products are not readily 
available at the rural retail stores. Taking such opportunities, locally manufactured imitated products are penetrating into the rural markets. For such reason, consumers have little or no choice but to buy the imitative products from their nearby retail stores. It is also witnessed that, the price of the copy products are sold at a lower price in comparison to the actual products' price. In such circumstances, it has been found that the rural consumers in spite of knowing and consuming the copy products, which are lower in terms of features, benefits, and quality, still they are satisfied with their purchase products because of the price affordability factor of the rural consumers.

When the respondents were asked about the new concepts of packaging and labeling, they desire to see national celebrities (cricketers, brand promoters, media personalities, etc.) on the product's label. It is also mentioned that middle aged and senior citizens wished to see moral messages which will inspire the youths to act morally and become socially responsible.

\section{Suggestions for Further Implications}

Some of the suggested views for further implications by the researchers' are mentioned below:

$>$ Rural consumers prefer communications in aesthetically appealing form. The appropriate and vivid colors in the packaging and package design provide them a cheerful feeling. The write-ups must be in the form of creative nature by visuals to attract them and the messages must be easily communicable which can be understood by the rural consumers. The use of the local language in terms of displaying words can be more effective for the rural markets as the use of foreign languages may not always be understandable to the rural consumers.

$>$ For catering the rural consumers, sachet packets and smaller versions of the personal care products are considered as a convenient size as it is within the affordability reach of the consumers.

$>$ In rural markets, the packaging is considered more effectual than the advertisements, as it can set brand recognition among the consumers. Based on the psychological aspects of the rural consumers, they actually believe in what they visually see and physically touch the product by themselves. Therefore, marketers of different personal care products can introduce such kind of package design which can be transparent in nature, therefore consumers can view the products from outward and texture of the products can be felt, which can eventually minimize the concern of the deceptive packaging issues among the rural consumers.

$>$ Copy products are always a concern for the marketers and if the copy products are penetrated to a greater extent in the rural markets, it becomes a severe issue for the brand marketers to control it. Due to lack of proper availability of the personal care products in the rural markets, many locally manufactured copy products have penetrated the markets. To control this severe situation, marketers need to develop their distribution network system, so that the genuine branded products can reach the rural markets and capture the rural retail shelves, thus making the products noticeable for the consumers to choose from the given options. In addition to this, FMCG Companies need to appoint efficient Sales Representatives to control and monitor the rural markets' trading operations such as the process of replenishing the available stocks and making products visible at the retail points. Proper training and authority delegation to monitor the rural retail outlets can enhance the market penetration of the branded products, thus controlling the situation and eventually minimizing the consumption of the copy products.

From the rural market perspectives, if the branded companies endorse celebrities or create brand characters, then the issue of copy products can be controlled and minimized. Renowned celebrities can be endorsed by the companies or the usage of specific symbolic characters can be initiated by the brand marketers. Their images can be imprinted on the product's label and by doing so, the actual products can be visually differentiable from other copy products which are also simultaneously available in the market.

$>$ One of the feasible mechanisms to make the personal care products more available in the rural markets is to aware the rural retailers. Rural retailers are considered as one of the Trustworthy sources for the rural 
consumers. These retailers, who sometimes have close ties with the consumers residing in the nearby localities, give advice to the consumers in terms of product selection and purchase. If these rural retailers are provided with different incentives in the form of sales commission, gifts, and other promotional merchandises, then the retailers will be encouraged to pursue and eventually convince their local customers to buy the different branded products. Thus, educating the retailers will make the actual products available at the rural retail stores and control the sales of copy products.

\section{Conclusion}

It is suggested to the marketers of the personal care products, that they should not only consider the packaging as the sole factor for the success of the product, consequently they should contemplate on the other marketing aspects at the time of launching a new product or rebranding a product to their prospective customers. On further research, the marketers can incorporate strategies that how packaging and labeling aspects can help the consumers to recall and reinforce them to recognize a brand under different situations.

\section{References}

[1] Pradeep K. (2012), "Rural Marketing", $2^{\text {nd }}$ Edition, Pearson Publication, pp. xix.

[2] Underwood, R. L., Klein, N. M. and Burke, R. R. (2001), "Packaging communication: attentional effects of product imagery”, Journal of Product \& Brand Management, Vol.10 (7), pp. 403-422. https://doi.org/10.1108/10610420110410531

[3] Orth, U. R., and Malkewitz, K. (2008). "Holistic package design and consumer brand impressions", Journal of Marketing, 72(3), pp. 64-81.

https://doi.org/10.1509/jmkg.72.3.64

[4] Rundh, B. (2005) “The multi-faceted dimension of packaging”, British Food Journal, 107 (9), pp. 670-684. https://doi.org/10.1108/00070709810204101

[5] Walter, N., Nadine, T. and Chu, G. (2013). "Brand experience's influence on customer satisfaction and loyalty: a mirage in marketing research?” International journal of management research and business strategy, pp. 1-17.

[6] Nancarrow, C., Wright, L. and Brace, I. (1998) 'Gaining Competitive Advantage from Packaging and Labeling in Marketing Communications”, British Food Journal 100 (2), pp. 110-18. https://doi.org/10.1108/00070709810204101

[7] Kotler, P., Armstrong, G., Saunders, J. and Wong, V. (2005) Principles of Marketing, $4^{\text {th }}$ European edition, Pearson Education Limited.

[8] Kotler, P. and Armstrong, G. (2008) Principles of Marketing, $12^{\text {th }}$ edition, Pearson Education Inc.

[9] Sonsino, S. (1990), "Packaging Design: Graphics, Materials, Technology", London: Thames and Hudson, ISBN 0500235805, pp. 190.

[10] Sauvage, F. (1996),"The marketing aspect of packaging", In Food packaging technology (Vol. 1). United States: VHC Publishers, pp. 33-47.

[11] Rizwan R. A., Parmar V. and Muhammad A. (2014), "Impact of Product Packaging on Consumer's Buying Behavior”, European Journal of Scientific Research 120 (2): pp. 145-157.

[12] Underwood, R. L., Klein, N. M. and Burke R. R., (2001) "Packaging communication: Attentional effects of product imagery", Journal of Product \& Brand Management, Vol. 10 Issue: 7, pp. 403-422.

https://doi.org/10.1108/10610420110410531

[13] Underwood, R. L. (2003),"The communicative power of product packaging: creating brand identity via lived and mediated experience", Journal of Marketing Theory \& Practice, Vol.11 (1), pp. 62-76.

https://doi.org/10.1080/10696679.2003.11501933

[14] Paula F.B. and Karen R.F. (2001), "Package Graphics and Consumer Product Beliefs", Journal of Business and Psychology, March 2001, Volume 15, Issue 3, pp. 467-489. 
[15] Underwood, R. L. (2003), "The communicative power of product packaging: creating brand identity via lived and mediated experience". Journal of Marketing Theory and Practice, winter, pp. 62-76. https://doi.org/10.1080/10696679.2003.11501933

[16] Kotler, P. and Armstrong, G. (2008), "Principles of Marketing", $12^{\text {th }}$ edition, Pearson Education Inc.

[17] Bassin, S. B. (1988),"Packaging: A Key Element in Added Value", Journal of Food Distribution Research, pp.6-11

[18] Underwood, R. L. and Ozanne, J. L. (1998), "Is your package an effective communicator? A normative framework for increasing the communicative competence of packaging", Journal of Marketing Communications, Vol. 4, pp. 207-220. https://doi.org/10.1080/135272698345762

[19] West's Encyclopedia of American Law, edition 2. Copyright 2008 The Gale Group.

[20] Pradeep, K. (2012), "Rural Marketing", $2^{\text {nd }}$ Edition, Pearson Publication, pp. 122.

[21] Manjunatha. K (2004), “Rural Marketing- Prospects”, Indian Journal of Marketing, Vol. XXXIV (6), June, pp. 8-10. 